\title{
Risk Factors and Medico-Economic Effect of Pancreatic Fistula after Pancreaticoduodenectomy
}

\author{
Renping Huang, ${ }^{1}$ Bing Liu, ${ }^{1}$ Hua Chen, ${ }^{2}$ Xuewei Bai, ${ }^{2}$ Rui Kong, ${ }^{2}$ Gang Wang, \\ Yongwei Wang, ${ }^{2}$ Bei Sun, ${ }^{2}$ and Yinghui Guan ${ }^{1}$ \\ ${ }^{1}$ Vascular Surgery, Department of General Surgery, The First Affiliated Hospital of Harbin Medical University, Harbin 150001, China \\ ${ }^{2}$ Department of Pancreatic and Biliary Surgery, The First Affiliated Hospital of Harbin Medical University, Harbin 150001, China
}

Correspondence should be addressed to Bei Sun; beisunn@163.com

Received 25 November 2014; Accepted 20 January 2015

Academic Editor: Gianfranco D. Alpini

Copyright (C) 2015 Renping Huang et al. This is an open access article distributed under the Creative Commons Attribution License, which permits unrestricted use, distribution, and reproduction in any medium, provided the original work is properly cited.

\begin{abstract}
The study aimed to uncover the risk factors for the new defined pancreatic fistula (PF) and clinical related PF (CR-PF) after pancreaticoduodenectomy (PD) surgery and to evaluate the medico-economic effect of patients. A total of 412 patients were classified into two groups according to different criteria, PF and NOPF according to PF occurrence: CR-PF (grades B and C) and NOCR-PF (grade A) based on PF severity. A total of 28 factors were evaluated by univariate and multivariate logistic regression test. Hospital charges and stays of these patients were assessed. The results showed that more hospital stages and charges are needed for patients in PF and CR-PF groups than in NOPF and NOCR-PF groups $(P<0.05)$. The excessive drinking, soft remnant pancreas, preoperative albumin, and intraoperative blood transfusion are risk factors affecting both PF and CR-PF incidence. More professional surgeons can effectively reduce the PF and CR-PF incidence. Patients with PF and CR-PF need more hospital costs and stages than that in NOPF and NOCR-PF groups. It is critical that surgeons know the risk factors related to PF and CR-PF so as to take corresponding therapeutic regimens for each patient.
\end{abstract}

\section{Introduction}

Pancreaticoduodenectomy (PD) is performed for treatment of patients with benign and malignant pancreatic and periampullary diseases. Despite improved surgical technique and postoperative care, the mortality of PD is high with mortality rate up to $30 \%$, due to its complex and challenging surgical procedure and high incidence of postoperative complications [1-4].

Pancreatic fistula $(\mathrm{PF})$ is the one of the most frequent complications of $\mathrm{PD}$ and occurs when pancreatic anastomosis fails to heal during surgery $[5,6]$. A definition and clinical classification of PF were proposed by the international study group of PF (ISGPF) in July, 2005 [1]. PF is defined as either a measurable drainage from an operatively place or a continuous placed percutaneous drain with amylase at least $3 \times$ normal serum activity 3 days postoperatively. The ISGPF classified the PF severity into grades $\mathrm{A}, \mathrm{B}$, and $\mathrm{C}$ based on the symptoms and treatment demand: grade $\mathrm{A}$ of
$\mathrm{PF}$ is transient, asymptomatic fistulas, just with elevated drain amylase levels; grade B is clinical apparent fistulas that need diagnostic assessment and therapeutic management; grade $\mathrm{C}$ is severe and requires major deviations in clinical management. Patient, who is diagnosed as grades $\mathrm{B}$ and $\mathrm{C}$, develops a clinical relevant PF (CR-PF).

The treatment of $\mathrm{PF}$ with an incidence ranging from 9.9\% to $28.5 \%$ [7] will no doubt prolong the postoperative recovery time and hospital stays and elevate the hospital cost and mortality of PD patients. Recent literatures have suggested that many factors could influence PF after PD, such as age, sex, operative time, anastomotic technique, intraoperative blood loss, remnant pancreas texture, use of somatostatin, jaundice, and surgeons experience [3, 8-12]. However, the research about if these risk-related factors have impact on the new defined and classified PF was relatively deficient. To evaluate the potential risk factors for PF and CR-PF patients after PD and to further access the medico-economic consequences of these patients, we collected data of 412 
patients who underwent PD during January 2007 and June 2014 and analyzed by the univariate and multivariate tests in the present study.

\section{Materials and Methods}

2.1. Patient Selection and Characteristics. Data of consecutive patients who underwent PD surgery at our hospital between January 2007 and June 2014 was collected in our study. Patients were excluded if (a) they had incomplete information; (b) they performed entire pancreatectomy; (c) they died during the PD operation or after operation within 3 days. According to these exclusion criteria, 34 patients were excluded.

Medical records of included patients were entered into a database, including gender, ages, body mass index (BMI), smoking status, alcohol drinking status (excessive drinking or not: excessive drinking is defined blood alcoholicity of more than 0.08), preoperative complications (such as coronary heart disease: this disease was determined by confirmed history of myocardial infarction, angina, or coronary revascularization), pathological diagnosis, diseased region, operative duration, amount of intraoperative bleeding, amount of intraoperative blood transfusion, residual pancreatic texture, pancreatic duct diameter, biochemical index in pre- and postoperation, volume of abdominal drainage, amylase content in abdominal drainage, postoperative regimen, and hospital stays and hospital charges. These patients with the occurrence of PF were grouped into PF. The rest of PD patients without $\mathrm{PF}$ the occurrence of were defined as NOPF and grouped into NOPF. CR-PF was defined as PF patients diagnosed as grade $\mathrm{B}$ fistulas and grade $\mathrm{C}$ fistulas that needed clinical intervention, and NOCR-PF were defined as non-PF patients and grade A PF patients that did not need clinical intervention.

2.2. Surgical Methods and Postoperative Care. PD was performed with or without pylorus-preservation (PP) by either laparoscopic operation or laparotomy. The reconstruction of digestive tract was conducted by anastomosis including binding anastomosis to the jejunum, end-end invagination anastomosis, end-side invagination anastomosis, and ductmucosa anastomosis. Pancreatic duct stent was applied in some patients. One or two drainage tubes were placed at the anastomotic stoma of all surgeries.

Surgeons who performed PD operations $\geq 10$ times per year were considered as professional, the others were considered as nonprofessional. Among all PD operations of our patients, 228 were performed by the professional surgeons and 184 were performed by unprofessional surgeons. Patients who had more than $300 \mu \mathrm{mol} / \mathrm{L}$ total bilirubin underwent biliary drainage during the operation. Those whose serum albumin was less than $30 \mathrm{~g} / \mathrm{L}$ in perioperative period were supplemented with albumin. Patients with hemoglobin less than $70 \mathrm{~g} / \mathrm{L}$ in perioperative period were treated with transfusion. Some patients were treated with somatostatin after surgery.

2.3. Statistical Analysis. Statistical analysis was performed by SPSS version 18.0 software. Data were expressed as $x \pm s$.
Categorical variables were analyzed by Fisher's exact test and chi-square test, and comparison of quantitative variables was analyzed by independent sample $t$-test. Variables reaching a $P$ value of $<0.05$ in a univariate analysis were included in the multivariate analysis by using a logistic regression model. The results of logistic regression model were assessed for independence of risk factors. Statistical significance was defined at the $P<0.05$ level.

\section{Results}

3.1. Demographic Characteristics of PD Patients. A total of 412 patients (260 men and 152 women) who underwent PD, with a mean age of 56 years (range from 22 to 79) undergoing PD between January 2007 and June 2014 were enrolled in our study. PF occurred in 126 (30.58\%) of them, who were grouped into PF. The other 286 (69.42\%) patients without the occurrence of PF were grouped into NOPF. Details regarding the characteristics of these patients were listed in Table 1. Among PF patients, 52 were diagnosed as A grade, 58 were diagnosed as B grade, and 16 were diagnosed as $\mathrm{C}$ grade. There were no significant statistical differences in genders, age groups $(<70$ and $\geq 70)$, and BMI between PF and NOPF groups, as well as CR-PF and NOCR-PF groups (Table 1). Unfortunately, 9 of them (2.18\%) died after surgery.

3.2. Potential-Related Factors for PF. Univariate logistic regression analysis showed that (Table 2(a)) there were significant associations between PF occurrence rates and patientrelated factors of excessive drinking $(P=0.029)$, coronary heart disease $(P=0.029)$, and preoperative albumin $(P=$ 0.006). Among comorbidities, a history of cholangitis, cholecystitis, jaundice, hypertension, or diabetes mellitus was similar in PF and NOPF groups. Besides, the smoking habits, preoperative serum bilirubin, postoperative serum albumin, primary site of disease, pathologic diagnosis, and pancreatic duct diameter were also found to have no association with PF incidence.

Univariate logistic regression analysis of operative- and therapeutic-related factors in $\mathrm{PF}$ and NOPF groups was showed in Table 2(b). There was no significant difference in $\mathrm{PF}$ rates between the preoperative biliary drainage treatment or not. Early jejunal nutrition, operative time, and use of somatostatin after PD were also found to have no correlation with PF rates. On the contrary, the pancreatic duct stent drainage methods, excision methods, anastomosis methods, intraoperative blood loss $(P=0.003)$, intraoperative blood transfusion $(P=0.000)$, pancreatic duct stent drainage $(P=$ $0.000)$, excision methods $(P=0.016)$, methods of anastomosis $(P=0.005)$, intraoperative blood transfusion $(P=0.000)$, laparoscopic operation or not $(P=0.002)$, and professional group or not $(P=0.000)$ markedly influenced the rate of $P F$.

3.3. Independence Risk Factors for PF. Based on the results of the above univariate analysis, additional multivariate analysis was performed for evaluating the independence of risk factors. As is showed in Table 3, both the excessive drinking and coronary heart disease were proved to be the independent 
TABLE 1: Demographic characteristics description.

\begin{tabular}{|c|c|c|c|c|c|c|c|c|}
\hline Variants & $\begin{array}{c}\text { PF } \\
\text { No. (\%) }\end{array}$ & $\begin{array}{c}\text { NOPF } \\
\text { No. }(\%)\end{array}$ & $\begin{array}{c}\text { Total } \\
\text { No. }(\%)\end{array}$ & $\chi^{2}(P$ value $)$ & $\begin{array}{c}\text { CR-PF } \\
\text { No. }(\%) \\
\end{array}$ & $\begin{array}{c}\text { NOCR-PF } \\
\text { No. }(\%)\end{array}$ & $\begin{array}{c}\text { Total } \\
\text { No. (\%) }\end{array}$ & $\chi^{2}(P$ value $)$ \\
\hline \multicolumn{9}{|l|}{ Gender } \\
\hline Male & $83(65.9)$ & 177 (61.9) & $260(63.1)$ & \multirow[t]{2}{*}{$0.597(0.440)$} & $44(59.5)$ & $216(63.9)$ & $260(63.1)$ & \multirow[t]{2}{*}{$0.515(0.473)$} \\
\hline Female & $43(34.1)$ & $109(38.1)$ & $152(36.9)$ & & $30(40.5)$ & $122(36.1)$ & $152(36.9)$ & \\
\hline \multicolumn{9}{|l|}{ Age (year) } \\
\hline$<70$ & $113(89.7)$ & $259(90.6)$ & $372(90.3)$ & \multirow[t]{2}{*}{$0.077(0.782)$} & $65(87.8)$ & $307(90.8)$ & $372(90.3)$ & \multirow[t]{2}{*}{$0.619(0.431)$} \\
\hline$\geq 70$ & $13(10.3)$ & $27(9.4)$ & $40(9.7)$ & & $9(12.2)$ & $31(9.2)$ & $40(9.7)$ & \\
\hline \multicolumn{9}{|l|}{ BMI } \\
\hline$<18.5$ & $14(11.1)$ & $41(14.3)$ & $55(13.3)$ & \multirow{3}{*}{$1.951(0.377)$} & $9(12.2)$ & $46(13.6)$ & $55(13.3)$ & \multirow{3}{*}{$0.328(0.849)$} \\
\hline $18.5-25$ & $90(71.4)$ & $208(72.7)$ & $298(72.3)$ & & $53(71.6)$ & $245(72.5)$ & $298(72.3)$ & \\
\hline$\geq 25$ & $22(17.5)$ & 37 (12.9) & $59(14.3)$ & & $12(16.2)$ & $47(13.9)$ & $59(14.3)$ & \\
\hline
\end{tabular}

PF: patients undergoing pancreatic fistula after pancreaticoduodenectomy (PD); NOPF: PD patients without PF occur; CR-PF: PF patients diagnosed as grade $\mathrm{B}$ fistulas and grade C fistulas; NOCR-PF: non-PF patients and grade A PF patients; BMI: body mass index.

risk factors for $\mathrm{PF}$ with odds ratio (ORs) of 0.390 (95\% CI $=(0.210-0.724), P=0.003)$ and $0.324(95 \% \mathrm{CI}=(0.127-$ $0.828), P=0.018)$, respectively. The preoperative albumin $(P=0.007)$ was significantly higher in the PF group than in the NOPF group (Table 3(a)). More intraoperative blood transfusion $(P=0.000)$ and harder remnant pancreas texture $(P=0.037)$ significantly reduced the PF risk. In addition, different methods of anastomosis, laparoscopic operation, and professional group were also included in the independent risk factors affecting PF $(P=0.026)$. Though pancreatic duct stent drainage and excision method were proved to be associated with PF in univariate analysis, the multivariate analysis showed that they were not independent risk factors $(P>0.05)$ (Table 3(b)).

3.4. Potential-Related Factors for CR-PF. Univariate logistic regression analysis showed that (Table 3(a)) the patient characteristics such as cholangitis $(P=0.002)$, preoperative serum albumin $(P=0.000)$, and texture of the remnant pancreas $(P=0.013)$ were significantly related to the CRPF. The other patient characteristics, for example, smoking, excessive drinking, cholecystitis, jaundice, coronary heart disease, hypertension, diabetes mellitus, preoperative serum total bilirubin, preoperative hemoglobin, postoperative serum albumin, primary site of disease, pathologic diagnosis, and diameter of pancreatic duct, had no influence on CR-PF occurrence (all $P>0.05$ ).

The operative and therapeutic risk factors such as intraoperative blood loss $(P=0.004)$, intraoperative blood transfusion $(P=0.002)$, pancreatic duct stent drainage $(P=0.007)$, and professional group were associated with an increased incidence of CR-PF $(P=0.000)$, while the left factors were found to have no significant association with the risk of CRPF (Table 3(b)).

3.5. Independence Risk Factors for ORPF. When assessing the independent effect of the potential risk factors on ORPF occurrence in multivariate analysis, cholangitis, preoperative albumin, intraoperative blood transfusion, texture of the remnant pancreas, and professional group or not were the significant associated factors (all $P<0.05$ ), whereas the effect of pancreatic duct stent drainage methods had no independent effect on ORPF.

3.6. Hospital Charges and Hospital Stays. Mean hospital stays were shorter in the NOPF group and NOCR-PF patients than in the PF and CR-PF patients, respectively (Table 4). By use of nonparametric test analysis, there were significant differences in hospital stays between PF and NOPF, as well as between CR-PF and NOCR-PF (both $P$ values were 0.000 ). The mean charges of the PF and NOPF patients were 56323.47 RMB and $83347.93 \mathrm{RMB}$, respectively, which exhibited significant difference with each other by $t$ text $(P=0.000)$. Similarly, significant difference was found between CR-PF and NOCRPF groups as well $(P=0.001)$, with mean hospital charges of RMB 61339.84 and 81448.18 , respectively.

\section{Discussion}

Effective management of PF has proven to be one of the most intractable challenges after PD surgery. Confront with this adversity, there has been a shift therapeutic regimen for management of PF, from a reactive "wait and see" to a proactive strategy that relies on early anticipation and timely prevention $[9,13]$. However, this approach depended on assumption and prediction of the risk for PF development. In the present study, we collected clinical data of 412 patients in our hospital, analyzed the potential risk factors associated with PF and CR-PF, and evaluated the medico-economic effect on these patients. Our results showed that the excessive drinking, coronary heart disease, preoperative albumin, intraoperative blood transfusion, texture of the remnant pancreas, methods of anastomosis, laparoscopic operation, and professional group were independently associated with PF occurrence. Among these risk factors of PF, the preoperative albumin, intraoperative blood transfusion, texture of the remnant pancreas, and professional group were significantly and independently associated with CR-PF. Though history of cholangitis in patients was found insignificantly related 
TABLE 2: Analysis for potential-related risk of pancreaticocutaneous fistula (PF) factors (univariate and multivariate analysis).

(a) Patient-related factors for PF

\begin{tabular}{|c|c|c|c|c|c|c|}
\hline \multirow{2}{*}{ Variants } & \multirow{2}{*}{$\begin{array}{c}\text { PF } \\
\text { No. (\%) }\end{array}$} & \multirow{2}{*}{$\begin{array}{c}\text { NOPF } \\
\text { No. (\%) }\end{array}$} & \multicolumn{2}{|c|}{ Univariate analysis } & \multicolumn{2}{|c|}{ Multivariate analysis } \\
\hline & & & $\mathrm{OR}_{\mathrm{adj}}(95 \% \mathrm{CI})$ & $P$ & $\mathrm{OR}_{\mathrm{adj}}(95 \% \mathrm{CI})$ & $P$ \\
\hline \multicolumn{7}{|l|}{ Smoking } \\
\hline Yes & $34(27.0)$ & $68(23.8)$ & 1 & \multirow[t]{2}{*}{0.499} & & \\
\hline No & $92(73.0)$ & $218(76.2)$ & $0.847(0.524-1.370)$ & & & \\
\hline \multicolumn{7}{|c|}{ Heavy smoking (cigarettes/day) } \\
\hline$\geq 20$ & $24(19.0)$ & $39(13.6)$ & 1 & \multirow[t]{2}{*}{0.17} & & \\
\hline$<20$ & $102(81.0)$ & $247(86.4)$ & $0.675(0.385-1.184)$ & & & \\
\hline Excessive drinking & & & & & & 0.003 \\
\hline Yes & $35(27.8)$ & $53(18.5)$ & 1 & 0.029 & 1 & \\
\hline No & $91(72.2)$ & $233(81.5)$ & $0.577(0.352-0.947)$ & & $0.390(0.210-0.724)$ & \\
\hline \multicolumn{7}{|l|}{ Cholangitis } \\
\hline Yes & $21(16.7)$ & $29(10.1)$ & 1 & \multirow[t]{2}{*}{0.06} & & \\
\hline No & $105(83.3)$ & $257(89.9)$ & $0.577(0.303-1.024)$ & & & \\
\hline \multicolumn{7}{|l|}{ Cholecystitis } \\
\hline Yes & $105(83.3)$ & $213(74.5)$ & 1 & \multirow[t]{2}{*}{0.054} & & \\
\hline No & $21(16.7)$ & $73(25.5)$ & $0.588(0.342-1.010)$ & & & \\
\hline \multicolumn{7}{|l|}{ Jaundice } \\
\hline Yes & $87(69.0)$ & $202(70.6)$ & 1 & \multirow[t]{2}{*}{0.671} & & \\
\hline No & $39(31.0)$ & $84(29.4)$ & $1.104(0.698-1.747)$ & & & \\
\hline Coronary heart disease & & & & & & 0.018 \\
\hline Yes & $16(12.7)$ & $16(5.6)$ & 1 & 0.029 & 1 & \\
\hline No & $110(87.3)$ & $270(94.4)$ & $0.441(0.211-0.919)$ & & $0.324(0.127-0.828)$ & \\
\hline \multicolumn{7}{|l|}{ Hypertension } \\
\hline Yes & $17(13.6)$ & $26(9.1)$ & 1 & \multirow[t]{2}{*}{0.353} & & \\
\hline No & $108(86.4)$ & $259(90.9)$ & $0.728(0.373-1.422)$ & & & \\
\hline \multicolumn{7}{|l|}{ Diabetes mellitus } \\
\hline Yes & $14(11.2)$ & $27(9.5)$ & 1 & \multirow[t]{2}{*}{0.624} & & \\
\hline No & $111(88.8)$ & $257(90.5)$ & $0.842(0.424-1.674)$ & & & \\
\hline \multicolumn{7}{|c|}{ Preoperative serum total bilirubin $(\mu \mathrm{mol} / \mathrm{L})$} \\
\hline$\leq 17.1$ & $28(22.2)$ & $63(22.0)$ & 1 & \multirow[t]{2}{*}{0.83} & & \\
\hline$>17.1$ & $98(77.8)$ & $223(78.0)$ & $0.946(0.568-1.573)$ & & & \\
\hline \multicolumn{7}{|c|}{ Preoperative hemoglobin $(\mathrm{g} / \mathrm{L})$} \\
\hline$<90$ & $3(2.4)$ & $7(2.4)$ & 1 & \multirow[t]{2}{*}{0.964} & & \\
\hline$\geq 90$ & $123(97.6)$ & $279(97.6)$ & $1.032(0.261-4.087)$ & & & \\
\hline Preoperative serum albu & & & & & & \\
\hline$<30$ & $10(7.9)$ & $6(2.1)$ & 1 & 0.006 & 1 & 0.007 \\
\hline$\geq 30$ & $116(92.1)$ & $280(97.9)$ & $0.235(0.083-0.666)$ & & $0.182(0.053-0.626)$ & \\
\hline Postoperative serum alb & & & & & & \\
\hline$<30$ & $51(40.5)$ & $93(32.5)$ & 1 & 0.095 & & \\
\hline$\geq 30$ & $75(59.5)$ & $193(67.5)$ & $0.689(0.445-1.067)$ & & & \\
\hline Primary site of disease & & & & & & \\
\hline Caput pancreatis & $59(46.8)$ & $129(45.1)$ & 1 & 4 & & \\
\hline Duodenum & $34(27.0)$ & $89(31.1)$ & $0.815(0.492-1.349)$ & $0.0 / 4$ & & \\
\hline Biliary ducts & $33(26.2)$ & $68(23.8)$ & $1.019(0.605-1.717)$ & & & \\
\hline
\end{tabular}


(a) Continued.

\begin{tabular}{|c|c|c|c|c|c|c|}
\hline \multirow{2}{*}{ Variants } & \multirow{2}{*}{$\begin{array}{c}\text { PF } \\
\text { No. (\%) }\end{array}$} & \multirow{2}{*}{$\begin{array}{c}\text { NOPF } \\
\text { No. (\%) }\end{array}$} & \multicolumn{2}{|c|}{ Univariate analysis } & \multicolumn{2}{|c|}{ Multivariate analysis } \\
\hline & & & $\mathrm{OR}_{\text {adj }}(95 \% \mathrm{CI})$ & $P$ & $\mathrm{OR}_{\mathrm{adj}}(95 \% \mathrm{CI})$ & $P$ \\
\hline \multicolumn{7}{|l|}{ Pathologic diagnosis } \\
\hline Caput pancreatis cancer & $48(38.1)$ & $91(31.8)$ & 1 & & & \\
\hline Duodenal cancer & $21(16.7)$ & $60(21.0)$ & $0.642(0.348-1.184)$ & & & \\
\hline Cholangiocarcinoma & $30(23.8)$ & $62(21.7)$ & $0.906(0.516-1.590)$ & 0.371 & & \\
\hline Pancreatitis & $4(3.2)$ & $21(7.3)$ & $0.416(0.134-1.294)$ & & & \\
\hline Carcinoma of ampulla & $6(4.8)$ & $20(7.0)$ & $0.588(0.220-1.570)$ & & & \\
\hline Others & $17(13.5)$ & $32(11.2)$ & $1.141(0.568-2.295)$ & & & \\
\hline Texture of the remnant pancreas & & & & 0.016 & & 0.037 \\
\hline Hard & $20(15.9)$ & $77(26.9)$ & 1 & & 1 & \\
\hline Soft & $106(84.1)$ & $209(73.1)$ & $1.964(1.136-3.394)$ & & $1.955(1.042-3.669)$ & \\
\hline Diameter of pancreatic duct (mm) & & & & 0.496 & & \\
\hline$<3$ & $68(54.0)$ & $142(49.7)$ & 1 & & & \\
\hline$\geq 3$ & $58(46.0)$ & $144(50.3)$ & $0.863(0.566-1.318)$ & & & \\
\hline
\end{tabular}

(b) Operative- and therapeutic-related factors for $\mathrm{PF}$

\begin{tabular}{|c|c|c|c|c|c|c|}
\hline \multirow{2}{*}{ Variants } & \multirow{2}{*}{$\begin{array}{c}\text { PF } \\
\text { No. }(\%)\end{array}$} & \multirow{2}{*}{$\begin{array}{c}\text { NOPF } \\
\text { No. (\%) }\end{array}$} & \multicolumn{2}{|c|}{ Univariate analysis } & \multicolumn{2}{|c|}{ Multivariate analysis } \\
\hline & & & $\mathrm{OR}_{\text {adj }}(95 \% \mathrm{CI})$ & $P$ & $\mathrm{OR}_{\mathrm{adj}}(95 \% \mathrm{CI})$ & $P$ \\
\hline \multicolumn{7}{|l|}{ Preoperative biliary drainage treatment } \\
\hline Yes & $13(10.3)$ & $25(8.7)$ & 1 & 0.535 & & \\
\hline No & $113(89.7)$ & $261(91.3)$ & $0.798(0.392-1.625)$ & & & \\
\hline Operative time ( $\mathrm{min}$ ) & & & & & & - \\
\hline$<295$ & $19(15.1)$ & $67(22.9)$ & 1 & 0.161 & & - \\
\hline$\geq 295$ & $107(84.9)$ & $226(77.1)$ & $0.669(0.380-1.177)$ & & & - \\
\hline Intraoperative blood loss (mL) & & & & 0.003 & - & - \\
\hline$<300$ & $35(27.8)$ & $121(42.3)$ & 1 & & - & - \\
\hline $300-600$ & $30(23.8)$ & $81(28.3)$ & $1.194(0.675-2.113)$ & & - & - \\
\hline $600-900$ & $28(22.2)$ & $45(15.7)$ & $2.089(1.139-3.830)$ & & - & - \\
\hline$\geq 900$ & $33(26.2)$ & $39(13.6)$ & $2.738(1.498-5.005)$ & & - & - \\
\hline Intraoperative blood transfusion $(\mathrm{mL})$ & & & & 0.000 & & 0.000 \\
\hline$<300$ & $41(32.5)$ & $136(47.6)$ & 1 & & 1 & \\
\hline $300-600$ & $23(18.3)$ & $67(23.4)$ & $1.112(0.616-2.008)$ & & $1.128(0.556-2.290)$ & 0.738 \\
\hline $600-900$ & $31(24.6)$ & $57(19.9)$ & $1.754(1.000-3.078)$ & & $2.574(1.318-5.025)$ & 0.006 \\
\hline$\geq 900$ & $31(24.6)$ & $26(9.1)$ & $3.711(1.969-6.995)$ & & $5.115(2.364-11.069)$ & 0.000 \\
\hline Pancreatic duct stent drainage & & & & 0.000 & & 0.394 \\
\hline No stent & $40(31.7)$ & $49(17.1)$ & 1 & & 1 & 0.570 \\
\hline Internal drainage & $77(61.1)$ & $174(60.8)$ & $0.518(0.313-0.856)$ & & $0.819(0.412-1.629)$ & 0.178 \\
\hline External drainage & $9(7.1)$ & $63(22.0)$ & $0.162(0.071-0.370)$ & & $0.476(0.161-1.403)$ & 0.624 \\
\hline Excision method & & & & 0.016 & & 0.624 \\
\hline Without PP & $108(85.7)$ & $266(93.0)$ & 1 & & 1 & \\
\hline With PP & $18(14.3)$ & $20(7.0)$ & $2.300(1.165-4.543)$ & & $1.240(0.524-2.932)$ & \\
\hline Methods of anastomosis & & & & 0.005 & & 0.026 \\
\hline Binding anastomosis & $3(2.4)$ & $22(7.7)$ & 1 & & 1 & \\
\hline End-side invagination anastomosis & $6(4.8)$ & $38(13.3)$ & $1.110(0.251-4.911)$ & & $2.428(0.439-13.432)$ & \\
\hline End-end invagination anastomosis & $106(84.1)$ & $194(67.8)$ & $3.922(1.143-13.456)$ & & $5.510(1.391-21.821)$ & \\
\hline Duct-mucosa anastomosis & $11(8.7)$ & $32(11.2)$ & $2.396(0.595-9.642)$ & & $7.918(1.619-38.722)$ & \\
\hline Laparoscopic operation & & & & 0.002 & & 0.034 \\
\hline Yes & $10(7.9)$ & $3(1.0)$ & 1 & & 1 & \\
\hline No & $116(92.1)$ & $283(99.0)$ & $0.128(0.034-0.477)$ & & $0.188(0.040-0.883)$ & \\
\hline
\end{tabular}


(b) Continued.

\begin{tabular}{|c|c|c|c|c|c|c|}
\hline \multirow{2}{*}{ Variants } & \multirow{2}{*}{$\begin{array}{c}\text { PF } \\
\text { No. (\%) }\end{array}$} & \multirow{2}{*}{$\begin{array}{c}\text { NOPF } \\
\text { No. (\%) }\end{array}$} & \multicolumn{2}{|c|}{ Univariate analysis } & \multicolumn{2}{|c|}{ Multivariate analysis } \\
\hline & & & $\mathrm{OR}_{\mathrm{adj}}(95 \% \mathrm{CI})$ & $P$ & $\mathrm{OR}_{\text {adj }}(95 \% \mathrm{CI})$ & $P$ \\
\hline Early jejunal nutrition & & & & 0.065 & & \\
\hline Yes & $25(19.8)$ & $81(28.3)$ & 1 & & & \\
\hline No & $101(80.2)$ & $205(71.7)$ & $1.617(0.970-2.694)$ & & & \\
\hline Use of somatostatin after PD & & & & 0.059 & & \\
\hline Yes & $84(66.7)$ & $161(56.3)$ & 1 & & & \\
\hline No & $42(33.3)$ & $125(43.7)$ & $0.655(0.422-1.017)$ & & & \\
\hline Professional group & & & & 0.000 & & 0.000 \\
\hline Yes & $38(30.2)$ & $190(66.4)$ & 1 & & 1 & \\
\hline No & $88(69.8)$ & $96(33.6)$ & $4.718(2.985-7.457)$ & & $3.925(2.250-6.847)$ & \\
\hline
\end{tabular}

-: the multivariate analysis of intraoperative blood loss was not performed in this study because of its corresponding relationship with intraoperative blood transfusion. Missing values: 3 diabetes mellitus patients and 2 hypertension patients were missing. OR: odds ratio; CI: confidence interval; $\mathrm{OR}_{\text {adj }}$ : adjusted ORs presented with $95 \%$ CI.

with PF, it was one of the risk factors that affected CR-PF significantly.

Although risk factors for PF and CR-PF have historically been reported in the literature, their relevance in application has been hampered by definitions of fistula [14]. Actually, several studies have tried to identify the risk factors associated with the PF development and many risk factors have been proposed. However, only a few factors are independent factors of PF and they vary among different studies. In the present study, total occurrence rate of PF after PD surgery was $30.58 \%$, which was slightly higher than previous results. The reason may be explained by the different definitions of PF. Though a normalized definition was proposed by ISGPF, the definition of PF might in some case not be specific, because it includes asymptomatic patients who are not clinically ill [6]. Therefore, the study of risk factors affecting grades $\mathrm{B}$ and $\mathrm{C}$ will be more meaningful in clinical practice.

Generally, PF risk evaluation begins in the preoperative setting, such as patient-related factors. In this study, we retrospectively analyzed the conditions of PF patients before PD surgery and found that the preoperative serum albumin, history of coronary heart disease, and excessive drinking were the independent risk factors associated with PF. With respect to $\mathrm{CR}-\mathrm{PF}$, the independent risk factors were preoperative serum albumin and cholangitis.

Albumin in serum has properties of maintaining normal plasma osmotic pressure [15] and acid-base balance [16], antioxidant [17], scavenging free radical [18], and protecting microcirculation [19]. On the one hand, tissue edema caused by hypoproteinemia may lead to undesirable or anastomotic stoma healing and then increase the incidence of PF or CR-PF. On the other hand, the increased hypoproteinemia complications such as infection and diarrhea will influence the PF and CR-PF more or less.

There is evidence from the current literatures that cardiovascular disease is a risk factor for PF [20], which was consistent with our findings, while the effect of coronary heart disease on CR-PF was not significant. The reasons why coronary heart disease would be associated with PF are not well understood. Perhaps the cardiovascular and cerebrovascular diseases are surrogate for decreased visceral perfusion result in anastomotic ischemia, or perhaps the related medications to such patients compromise anastomotic healing [21]. Therefore, the association between cardiovascular disease and PF should be well explained by reliable evidence from clinical outcomes.

Animal experiments and epidemiological studies have suggested that alcohol had toxicity to pancreas [22, 23]. It was proved to be an independent risk factor for PF occurrence in our patients undergoing PD. There are several hypotheses on the toxicity mechanisms of ethanol to pancreas. (a) The ethanol has toxic effect on pancreatic acinar cells and disturbs its metabolism [24]. (b) The accumulation of pancreatic stone protein induced by ethanol produces ulceration and inflammation of the ductules, and the ductule then leads to atrophy, insufficiency, and fibrosis themselves [25]. (c) The disorders such as sphincter of Oddi dysfunction caused by ethanol have a connection with stenosis of ductule and regurgitation of duodenal juice [25]. (d) Excessive drinking will destroy the essential minerals and induce the oxygen radical in vivo in human, which are harmful to pancreas [24]. We believe that the excessive drinking effect on PF will be closely related to its effect on pancreas.

One of the interesting findings in our research is that patients with cholangitis will be more likely to suffer from CR-PF than noncholangitis patients. Generally, mucosa in biliary ducts is congestive in cholangitis patients, especially in patients with obstruction of biliary tract. Edema and inflammation usually happen in pancreatic tissues when the bile duct enlarged by obstruction. Therefore, it is harmful to conduct the anastomosis and CR-PF is likely to occur. In addition, cholangitis is usually accompanied with increased bacteria in the bile duct. The increased intraductal pressure can lead to bacteria translocation or endotoxemia in these patients [26], which may be another indirect factors affecting CR-PF occurrence.

The factors of pathologic diagnosis, texture of the remnant pancreas and diameter of pancreatic duct have been widely accepted as the related risk factors of PF [12, 2729]. Logistic analysis of regression showed that patients with soft texture of the remnant pancreas had higher PF and CR$\mathrm{PF}$ incidence than that in patients with hard texture. There 
TABLE 3: Analysis for potential risk factors of pancreaticocutaneous fistula (CR-PF) factors (univariate and multivariate analysis).

(a) Patient-related factors for CR-PF

\begin{tabular}{|c|c|c|c|c|c|c|}
\hline \multirow{2}{*}{ Variants } & \multirow{2}{*}{$\begin{array}{c}\text { CR-PF } \\
\text { No. (\%) }\end{array}$} & \multirow{2}{*}{$\begin{array}{c}\text { NOCR-PF } \\
\text { No. }(\%)\end{array}$} & \multicolumn{2}{|c|}{ Univariate analysis } & \multicolumn{2}{|c|}{ Multivariate analysis } \\
\hline & & & $\mathrm{OR}_{\mathrm{adj}}(95 \% \mathrm{CI})$ & $P$ & $\mathrm{OR}_{\mathrm{adj}}(95 \% \mathrm{CI})$ & $P$ \\
\hline Smoking & & & & 0.84 & & \\
\hline Yes & $19(25.7)$ & $83(24.6)$ & 1 & & & \\
\hline No & $55(74.3)$ & $255(75.4)$ & $0.942(0.529-1.678)$ & & & \\
\hline Heavy smoking (cigarettes/day) & & & & 0.191 & & \\
\hline$\geq 20$ & $15(20.3)$ & $48(14.2)$ & 1 & & & \\
\hline$<20$ & $59(79.3)$ & $290(85.8)$ & $0.651(0.342-1.239)$ & & & \\
\hline Excessive drinking & & & & 0.493 & & \\
\hline Yes & $18(24.3)$ & $70(20.7)$ & 1 & & & \\
\hline No & $56(75.7)$ & $268(79.3)$ & $0.813(0.449-1.470)$ & & & \\
\hline Cholangitis & & & & 0.002 & & \\
\hline Yes & $17(23.0)$ & $33(9.8)$ & 1 & & & \\
\hline No & $57(77.0)$ & $305(90.2)$ & $0.363(0.189-0.695)$ & & & \\
\hline Cholecystitis & & & & 0.075 & & 0.004 \\
\hline Yes & $63(85.1)$ & $255(75.4)$ & 1 & & 1 & \\
\hline No & $11(14.9)$ & $83(24.6)$ & $0.536(0.270-1.066)$ & & $0.321(0.150-0.690)$ & \\
\hline Jaundice & & & & 0.054 & & \\
\hline Yes & $45(60.8)$ & $244(72.2)$ & 1 & & & \\
\hline No & $29(39.2)$ & $94(27.8)$ & $1.673(0.991-2.825)$ & & & \\
\hline Coronary heart disease & & & & 0.284 & & \\
\hline Yes & $8(10.8)$ & $24(7.1)$ & 1 & & & \\
\hline No & $66(89.2)$ & $314(92.9)$ & $0.631(0.271-1.465)$ & & & \\
\hline Hypertension & & & & 0.572 & & \\
\hline Yes & $9(12.3)$ & $34(10.1)$ & 1 & & & \\
\hline No & $64(87.7)$ & $303(89.9)$ & $0.798(0.365-1.745)$ & & & \\
\hline Diabetes mellitus & & & & 0.163 & & \\
\hline Yes & $4(5.5)$ & $37(11.0)$ & 1 & & & \\
\hline No & $69(94.5)$ & $299(89.0)$ & $2.135(0.736-6.188)$ & & & \\
\hline Preoperative serum total bilirubin $(\mu \mathrm{mol} / \mathrm{L})$ & & & & 0.412 & & \\
\hline$\leq 17.1$ & $19(25.7)$ & $72(21.3)$ & 1 & & & \\
\hline$>17.1$ & $55(74.3)$ & $266(78.7)$ & $0.784(0.437-1.404)$ & & & \\
\hline Preoperative hemoglobin (g/L) & & & & 0.324 & & \\
\hline$<90$ & $3(4.1)$ & $7(2.1)$ & 1 & & & \\
\hline$\geq 90$ & $71(95.9)$ & $331(97.9)$ & $0.501(0.126-1.983)$ & & & \\
\hline Preoperative serum albumin $(\mathrm{g} / \mathrm{L})$ & & & & 0 & & 0.000 \\
\hline$<30$ & $9(12.2)$ & $7(2.1)$ & 1 & & 1 & \\
\hline$\geq 30$ & $65(87.8)$ & $331(97.9)$ & $0.153(0.055-0.425)$ & & $0.107(0.031-0.363)$ & \\
\hline Postoperative serum albumin $(\mathrm{g} / \mathrm{L})$ & & & & 0.971 & & \\
\hline$<30$ & $26(35.1)$ & $118(34.9)$ & 1 & & & \\
\hline$\geq 30$ & $48(64.9)$ & $220(65.1)$ & $0.990(0.585-1.677)$ & & & \\
\hline Primary site of disease & & & & 0.935 & & \\
\hline Caput pancreatis & $34(45.9)$ & $154(45.6)$ & 1 & & & \\
\hline Duodenum & $23(31.1)$ & $100(29.6)$ & $1.042(0.580-1.872)$ & & & \\
\hline Biliary ducts & $17(23.0)$ & $84(24.9)$ & $0.917(0.483-1.738)$ & & & \\
\hline
\end{tabular}


(a) Continued.

\begin{tabular}{|c|c|c|c|c|c|c|}
\hline \multirow{2}{*}{ Variants } & \multirow{2}{*}{$\begin{array}{c}\text { CR-PF } \\
\text { No. }(\%)\end{array}$} & \multirow{2}{*}{$\begin{array}{c}\text { NOCR-PF } \\
\text { No. }(\%)\end{array}$} & \multicolumn{2}{|c|}{ Univariate analysis } & \multicolumn{2}{|c|}{ Multivariate analysis } \\
\hline & & & $\mathrm{OR}_{\mathrm{adj}}(95 \% \mathrm{CI})$ & $P$ & $\mathrm{OR}_{\mathrm{adj}}(95 \% \mathrm{CI})$ & $P$ \\
\hline Pathologic diagnosis & & & & 0.322 & & \\
\hline Caput pancreatis cancer & $28(37.8)$ & $111(32.8)$ & 1 & & & \\
\hline Duodenal cancer & $13(17.6)$ & $68(20.1)$ & $0.758(0.368-1.563)$ & & & \\
\hline Cholangiocarcinoma & $15(20.3)$ & $77(22.8)$ & $0.772(0.387-1.542)$ & & & \\
\hline Pancreatitis & $1(1.4)$ & $24(7.1)$ & $0.165(0.021-1.274)$ & & & \\
\hline Carcinoma of ampulla & $4(5.4)$ & $22(6.5)$ & $0.721(0.230-2.261)$ & & & \\
\hline Others & $13(17.6)$ & $36(10.7)$ & $1.432(0.671-3.054)$ & & & \\
\hline Texture of the remnant pancreas & & & & 0.013 & & 0.044 \\
\hline Hard & $9(12.2)$ & $88(26.0)$ & 1 & & 1 & \\
\hline Soft & $65(87.8)$ & $250(74.0)$ & $2.542(1.215-5.319)$ & & $2.316(1.205-5.234)$ & \\
\hline Diameter of pancreatic duct (mm) & & & & 0.400 & & \\
\hline$<3$ & $41(55.4)$ & $169(50.0)$ & 1 & & & \\
\hline$\geq 3$ & $33(44.6)$ & $169(50.0)$ & $0.805(0.485-1.334)$ & & & \\
\hline
\end{tabular}

(b) Operative- and therapeutic-related factors for CR-PF

\begin{tabular}{|c|c|c|c|c|c|c|}
\hline \multirow{2}{*}{ Variants } & \multirow{2}{*}{$\begin{array}{l}\text { CR-PF } \\
\text { No. }(\%)\end{array}$} & \multirow{2}{*}{$\begin{array}{c}\text { NOCR-PF } \\
\text { No. }(\%)\end{array}$} & \multicolumn{2}{|c|}{ Univariate analysis } & \multicolumn{2}{|c|}{ Multivariate analysis } \\
\hline & & & $\mathrm{OR}_{\mathrm{adj}}(95 \% \mathrm{CI})$ & $P$ & $\mathrm{OR}_{\mathrm{adj}}(95 \% \mathrm{CI})$ & $P$ \\
\hline Preoperative biliary drainage treatment & & & & 0.068 & & \\
\hline Yes & $11(14.9)$ & $27(8.0)$ & 1 & & & \\
\hline No & $63(85.1)$ & $311(92.0)$ & $0.497(0.235-1.054)$ & & & \\
\hline Operative time ( $\mathrm{min}$ ) & & & & 1.081 & & \\
\hline$<295$ & $11(14.9)$ & $68(20.1)$ & 1 & & & \\
\hline$\geq 295$ & $63(85.1)$ & $270(79.9)$ & $0.693(0.347-1.387)$ & & & \\
\hline Intraoperative blood loss (mL) & & & & 0.004 & - & - \\
\hline$<300$ & $20(27.0)$ & $136(40.2)$ & 1 & & - & - \\
\hline $300-600$ & $14(18.9)$ & $97(28.7)$ & $0.981(0.473-2.039)$ & & - & - \\
\hline $600-900$ & $20(27.0)$ & $53(15.7)$ & $2.566(1.279-5.148)$ & & - & - \\
\hline$\geq 900$ & $20(27.0)$ & $52(15.4)$ & $2.615(1.302-5.253)$ & & - & - \\
\hline Intraoperative blood transfusion $(\mathrm{mL})$ & & & & 0.002 & & 0.001 \\
\hline$<300$ & $19(25.7)$ & $158(46.7)$ & 1 & & 1 & \\
\hline $300-600$ & $18(24.3)$ & $72(21.3)$ & $2.079(1.030-4.196)$ & & $2.311(1.049-5.092)$ & 0.038 \\
\hline $600-900$ & $18(24.3)$ & $70(20.7)$ & $2.138(1.058-4.321)$ & & $2.657(1.207-5.851)$ & 0.015 \\
\hline$\geq 900$ & $19(25.7)$ & $38(11.2)$ & $4.158(2.008-8.609)$ & & $5.337(2.301-12.376)$ & 0.000 \\
\hline Pancreatic duct stent drainage & & & & 0.007 & & 0.542 \\
\hline No stent & $24(32.4)$ & $65(19.2)$ & 1 & & 1 & \\
\hline Internal drainage & $45(60.8)$ & $206(60.9)$ & $0.592(0.335-1.045)$ & & $0.692(0.359-1.334)$ & 0.272 \\
\hline External drainage & $5(6.8)$ & $67(19.8)$ & $0.202(0.073-0.562)$ & & $0.814(0.248-2.671)$ & 0.375 \\
\hline Excision method & & & & 0.068 & & \\
\hline Without PP & $63(85.1)$ & $311(92.0)$ & 1 & & & \\
\hline With PP & $11(14.9)$ & $27(8.0)$ & $2.011(0.949-4.264)$ & & & \\
\hline Methods of anastomosis & & & & 0.069 & & \\
\hline Binding anastomosis & $2(2.7)$ & $23(6.8)$ & 1 & & & \\
\hline End-side invagination anastomosis & $3(4.1)$ & $41(12.1)$ & $0.841(0.131-5.409)$ & & & \\
\hline End-end invagination anastomosis & $63(85.1)$ & $237(70.1)$ & $3.057(0.702-13.314)$ & & & \\
\hline Duct-mucosa anastomosis & $6(8.1)$ & $37(10.9)$ & $1.865(0.347-10.034)$ & & & \\
\hline Laparoscopic operation & & & & 0.231 & & \\
\hline Yes & $4(5.4)$ & $9(2.7)$ & 1 & & & \\
\hline No & $70(94.6)$ & $329(97.3)$ & $0.479(0.143-1.599)$ & & & \\
\hline
\end{tabular}


(b) Continued.

\begin{tabular}{|c|c|c|c|c|c|c|}
\hline \multirow{2}{*}{ Variants } & \multirow{2}{*}{$\begin{array}{l}\text { CR-PF } \\
\text { No. }(\%)\end{array}$} & \multirow{2}{*}{$\begin{array}{c}\text { NOCR-PF } \\
\text { No. }(\%)\end{array}$} & \multicolumn{2}{|c|}{ Univariate analysis } & \multicolumn{2}{|c|}{ Multivariate analysis } \\
\hline & & & $\mathrm{OR}_{\mathrm{adj}}(95 \% \mathrm{CI})$ & $P$ & $\mathrm{OR}_{\mathrm{adj}}(95 \% \mathrm{CI})$ & $P$ \\
\hline Early jejunal nutrition & & & & 0.238 & & \\
\hline Yes & $15(20.3)$ & $91(26.9)$ & 1 & & & \\
\hline No & $59(79.7)$ & $247(73.1)$ & $1.449(0.783-2.682)$ & & & \\
\hline Use of somatostatin after PD & & & & 0.069 & & \\
\hline Yes & $51(68.9)$ & $194(57.4)$ & 1 & & & \\
\hline No & $23(31.1)$ & $144(42.6)$ & $0.608(0.355-1.040)$ & & & \\
\hline Professional group & & & & 0.000 & & 0.000 \\
\hline Yes & $16(21.6)$ & $212(62.7)$ & 1 & & 1 & \\
\hline No & $58(78.4)$ & $126(37.3)$ & $6.099(3.362-11.066)$ & & $5.674(2.867-11.230)$ & \\
\hline
\end{tabular}

-: the multivariate analysis of intraoperative blood loss was not performed in this study because of its corresponding relationship with intraoperative blood transfusion. Missing values: 3 diabetes mellitus patients and 2 hypertension patients were missing. OR: odds ratio; CI: confidence interval; OR ${ }_{\text {adj }}$ : adjusted ORs presented with $95 \%$ CI.

TABLE 4: Hospital charges and hospital stays.

\begin{tabular}{lccc}
\hline & NOPF & PF & NOCR-PF \\
\hline & & Average hospital stays (d) & 0.004 \\
Normality test $P$ & 0.009 & 0.024 & 0.06 \\
$t$-test/nonparametric test $P$ & & $0.000^{\mathrm{a}}$ & $0.000^{\mathrm{b}}$ \\
Mean (d) & 22.25 & 39.08 & 23.33 \\
Standard deviation & & & 0.42 \\
\hline & & Average hospital charges & 0.279 \\
Normality test $P$ & 0.223 & 0.617 & 0.915 \\
$t$-test/nonparametric test $P$ & & $0.000^{\mathrm{a}}$ & $0.001^{\mathrm{b}}$ \\
Mean (yuan) & 56323.47 & 83347.93 & 61339.84 \\
Standard deviation & 24360.81 & 32007.30 & 28166.70 \\
\hline
\end{tabular}

Missing values: data missing for 8 patients in hospital charges. ${ }^{\mathrm{a}} \mathrm{P}$ value of nonparametric test between PF and NOPF groups; ${ }^{\mathrm{b}} \mathrm{P}$ value of $t$ test between NOCRPF and CR-PF groups.

are several explanations for this association. Firstly, a soft pancreas is more susceptible to injury and ischemia during operative dissection [29]. Meanwhile, exocrine function is usually preserved in the soft pancreas, leading to increased secretion of pancreatic juice and activation of proteolytic enzymes, which is more prone for PF development [30]. However, our data did not provide evidence to support pathologic diagnosis and diameter of pancreatic duct $(\geq 3 \mathrm{~mm}$ and $<3 \mathrm{~mm}$ ) of influence factors for PF and CR-PF. The relationship between them needs more studies in the future.

Blood transfusion in response to blood loss is considered to be an immunosuppressive effect. In our study, the intraoperative blood transfusion was mainly caused by intraoperative blood loss, preoperative anemia, coagulation disorders, and so forth. Though our results showed that the intraoperative blood transfusion was the risk factor influencing both PF and CR-PF, the full impact of intraoperative blood transfusion is not well understood. Rapid blood loss, as well as anemia and coagulation disorder, may cause ischemia and poor healing of the pancreatic anastomosis, because of tissue edema from aggressive blood replacement in a "rebound" fashion [29]. In addition, other adverse effects such as complications of blood transfusion, disseminated intravascular coagulation, and hemorrhagic tendency during intraoperative blood transfusion may increase the risk of PF and CR-PF after PD surgery.

Hypertension has been noted as one of the risk factors in previous studies $[31,32]$. They assumed that the pathophysiological effects of hypertension caused generalized atherosclerosis and therefore limited the microcirculation of the tissue. That will negatively affect the healing process of PD. However, in our study, we found no significant association between hypertension and postoperative PD. Therefore, we strongly recommended more studies to resolve these controversial results.

The PD surgery with laparoscope has been clinically applied since its first description by Gagner and Pomp [33] in $1994[34,35]$. The multivariate analysis of $13 \mathrm{PD}$ patients with laparoscope (PF: 10, CR-PF: 4) and 309 patients with laparotomy showed that more patients treated with laparoscope developed PF than that treated with laparotomy. Fortunately, the laparoscope treatment had no significant side effect on CR-PF. Limitations of this approach including inability to palpate the lesion, relatively narrow view, inaccurate location, and misestimates of tumor spread may be responsible for high PF occurrence. We believe that these limitations will be minimized as the experiential accumulation and technological improvement. 
Other operative- and therapeutic-related factors such as treatment of residual pancreatic, application of pancreatic duct stent drainage, methods of anastomose, use of somatostatin after PD, and excision methods have suggested associating with the PF incidence [21, 32, 36]. Analysis of these factors in our study revealed that just anastomose methods were associated with PF. The binding anastomosis was proved to be superior to end-side invagination anastomosis, end-end invagination anastomosis, and duct-mucosa anastomosis, because of its less PF incidence. Instead of suture, binding anastomosis can definitely minimize the leakage by avoiding any pinhole through the closure [37]. Furthermore, binding anastomosis avoids the regurgitation of pancreatic juice by maintaining higher blasting pressure in jejunum than other methods [38]. However, this method was found to have no relationship with CR-PF.

Unquestionably, the complex and difficult PD operation is a challenge to surgeons. Therefore the skilled and experienced surgeons will be important factors related to PF incidence. In our study, the PF and CR-PF incidence after PD surgery in professional group were 3 and 5.7 times more than nonprofessional group, respectively. The high-volume surgeons were proved to have lower PF rate $[39,40]$, probably due to more experience for surgeons. Therefore, it is necessary for training PD surgeons and establishing professional group in future.

Patients with PF, especially with CR-PF after PD surgery, usually have to prolong the hospital stages and pay more for external surgery than patients in NOPF or NOCR-PF group. Our study also showed more hospital stages and charges in PF and CR-PF groups than in NOPF and NOCR-PF groups. Future studies that address the charge and hospital stages are required, in light of the rapid increase of technology.

\section{Conclusion}

In summary, the excessive drinking, coronary heart disease, preoperative albumin, intraoperative blood transfusion $(>600 \mathrm{~mL})$, soft remnant pancreas, and laparoscopic operation were risk factors affecting PF incidence after PD. Binding anastomosis between remnant pancreas and jejunum can effectively reduce the PF incidence compared with the other anastomosis methods, such as end-side invagination anastomosis, end-end invagination anastomosis, and ductmucosa anastomosis. The risk factors such as cholangitis, hypoproteinemia, intraoperative blood transfusion volume $(>300 \mathrm{~mL})$, and soft remnant pancreas were significantly associated with CR-PF. Surgeons with more experience and profession can significantly reduce the PF and CR-PF incidence when they perform PD surgery. More hospital stages and charges in PF and CR-PF groups are needed than in NOPF and NOCR-PF groups. It is critical that surgeons know the risk factors related to PF and CR-PF so as to take corresponding therapeutic regimens for each patient.

\section{Conflict of Interests}

The authors declare that there is no conflict of interests regarding the publication of this paper.

\section{Acknowledgments}

This work was supported in part by grants from the Research Special Fund For Public Welfare Industry of Health (201202007); the Research Fund for the Doctoral Program of Higher Education of China (20122307110012); and the National Natural Science Foundation of China (81372613, 81170431, 81302057, and 81470887).

\section{References}

[1] C. Bassi, C. Dervenis, G. Butturini et al., "Postoperative pancreatic fistula: an international study group (ISGPF) definition," Surgery, vol. 138, no. 1, pp. 8-13, 2005.

[2] J. L. Cameron, T. S. Riall, J. Coleman, and K. A. Belcher, "One thousand consecutive pancreaticoduodenectomies," Annals of Surgery, vol. 244, no. 1, pp. 10-15, 2006.

[3] S. V. Shrikhande and M. A. D'Souza, "Pancreatic fistula after pancreatectomy: evolving definitions, preventive strategies and modern management," World Journal of Gastroenterology, vol. 14, no. 38, pp. 5789-5796, 2008.

[4] V. C. Njoku, T. J. Howard, C. Shen et al., "Pyogenic liver abscess following pancreaticoduodenectomy: risk factors, treatment, and long-term outcome," Journal of Gastrointestinal Surgery, vol. 18, no. 5, pp. 922-928, 2014.

[5] G. Balzano, A. Zerbi, G. Capretti, S. Rocchetti, V. Capitanio, and V. di Carlo, "Effect of hospital volume on outcome of pancreaticoduodenectomy in Italy," British Journal of Surgery, vol. 95, no. 3, pp. 357-362, 2008.

[6] G. Butturini, D. Daskalaki, E. Molinari, F. Scopelliti, A. Casarotto, and C. Bassi, "Pancreatic fistula: definition and current problems," Journal of Hepato-Biliary-Pancreatic Surgery, vol. 15, no. 3, pp. 247-251, 2008.

[7] N. Faccioli, G. Foti, E. Molinari et al., "Role of fistulography in evaluating pancreatic fistula after pancreaticoduodenectomy," British Journal of Radiology, vol. 85, no. 1011, pp. 219-224, 2012.

[8] C. M. Schmidt, E. S. Powell, C. T. Yiannoutsos et al., "Pancreaticoduodenectomy: a 20-year experience in 516 patients," Archives of Surgery, vol. 139, no. 7, pp. 718-727, 2004.

[9] M. P. Callery, W. B. Pratt, and C. M. Vollmer Jr., "Prevention and management of pancreatic fistula," Journal of Gastrointestinal Surgery, vol. 13, no. 1, pp. 163-173, 2009.

[10] E. C. H. Lai, S. H. Y. Lau, and W. Y. Lau, "Measures to prevent pancreatic fistula after pancreatoduodenectomy: a comprehensive review," Archives of Surgery, vol. 144, no. 11, pp. 1074-1080, 2009.

[11] S. M. Strasberg, D. C. Linehan, P.-A. Clavien, and J. S. Barkun, "Proposal for definition and severity grading of pancreatic anastomosis failure and pancreatic occlusion failure," Surgery, vol. 141, no. 4, pp. 420-426, 2007.

[12] N. O. MacHado, "Pancreatic fistula after pancreatectomy: definitions, risk factors, preventive measures, and managementreview," International Journal of Surgical Oncology, vol. 2012, Article ID 602478, 10 pages, 2012.

[13] W. B. Pratt, S. K. Maithel, T. Vanounou, Z. S. Huang, M. P. Callery, and C. M. Vollmer Jr., "Clinical and economic validation of the International Study Group of Pancreatic Fistula (ISGPF) classification scheme," Annals of Surgery, vol. 245, no. 3, pp. 443-451, 2007.

[14] C. Bassi, G. Butturini, E. Molinari et al., "Pancreatic fistula rate after pancreatic resection: the importance of definitions," Digestive Surgery, vol. 21, no. 1, pp. 54-59, 2004. 
[15] P. D. Navar and L. G. Navar, "Relationship between colloid osmotic pressure and plasma protein concentration in the dog," The American Journal of Physiology-Heart and Circulatory Physiology, vol. 233, no. 2, pp. H295-H298, 1977.

[16] J. Figge, T. H. Rossing, and V. Fencl, "The role of serum proteins in acid-base equilibria," Journal of Laboratory and Clinical Medicine, vol. 117, no. 6, pp. 453-467, 1991.

[17] M. Roche, P. Rondeau, N. R. Singh, E. Tarnus, and E. Bourdon, "The antioxidant properties of serum albumin," FEBS Letters, vol. 582, no. 13, pp. 1783-1787, 2008.

[18] M. Soriani, D. Pietraforte, and M. Minetti, "Antioxidant potential of anaerobic human plasma: role of serum albumin and thiols as scavengers of carbon radicals," Archives of Biochemistry and Biophysics, vol. 312, no. 1, pp. 180-188, 1994.

[19] M. W. Keller, S. S. Segal, S. Kaul, and B. Duling, "The behavior of sonicated albumin microbubbles within the microcirculation: a basis for their use during myocardial contrast echocardiography," Circulation Research, vol. 65, no. 2, pp. 458-467, 1989.

[20] M. L. DeOliveira, J. M. Winter, M. Schafer et al., "Assessment of complications after pancreatic surgery: a novel grading system applied to 633 patients undergoing pancreaticoduodenectomy," Annals of Surgery, vol. 244, no. 6, pp. 931-937, 2006.

[21] J. W. Lin, J. L. Cameron, C. J. Yeo, T. S. Riall, and K. D. Lillemoe, "Risk factors and outcomes in postpancreaticoduodenectomy pancreaticocutaneous fistula," Journal of Gastrointestinal Surgery, vol. 8, no. 8, pp. 951-959, 2004.

[22] G. A. Cote, D. Yadav, A. Slivka et al., "Alcohol and smoking as risk factors in an epidemiology study of patients with chronic pancreatitis," Clinical Gastroenterology and Hepatology, vol. 9, no. 3, pp. 266-273, 2011.

[23] D. Sophia, M. Gomathy, T. Shebin, P. Ragavendran, C. Arulraj, and V. K. Gopalakrishnan, "Effect of Emilia sonchifolia (Linn.)DC on alcohol-induced oxidative stress in pancreas of male albino rats," Asian Pacific Journal of Tropical Medicine, vol. 4, no. 12, pp. 973-977, 2011.

[24] A. Vonlaufen, J. S. Wilson, R. C. Pirola, and M. V. Apte, "Role of alcohol metabolism in chronic pancreatitis," Alcohol Research and Health, vol. 30, no. 1, pp. 48-54, 2007.

[25] T. Stevens, D. L. Conwell, and G. Zuccaro, "Pathogenesis of chronic pancreatitis: an evidence-based review of past theories and recent developments," American Journal of Gastroenterology, vol. 99, no. 11, pp. 2256-2270, 2004.

[26] Y. Kimura, T. Takada, Y. Kawarada et al., "Definitions, pathophysiology, and epidemiology of acute cholangitis and cholecystitis: tokyo guidelines," Journal of Hepato-Biliary-Pancreatic Surgery, vol. 14, no. 1, pp. 15-26, 2007.

[27] C. J. Yeo, J. L. Cameron, K. D. Lillemoe et al., "Does prophylactic octreotide decrease the rates of pancreatic fistula and other complications after pancreaticoduodenectomy? Results of a prospective randomized placebo-controlled trial," Annals of Surgery, vol. 232, no. 3, pp. 419-429, 2000.

[28] J. W. Denbo, W. S. Orr, B. L. Zarzaur, and S. W. Behrman, "Toward defining grade $\mathrm{C}$ pancreatic fistula following pancreaticoduodenectomy: Incidence, risk factors, management and outcome," HPB, vol. 14, no. 9, pp. 589-593, 2012.

[29] M. P. Callery, W. B. Pratt, T. S. Kent, E. L. Chaikof, and C. M. Vollmer Jr., "A prospectively validated clinical risk score accurately predicts pancreatic fistula after pancreatoduodenectomy," Journal of the American College of Surgeons, vol. 216, no. 1, pp. 1-14, 2013.

[30] S. E. Lee, J.-Y. Jang, C.-S. Lim et al., "Measurement of pancreatic fat by magnetic resonance imaging: predicting the occurrence of pancreatic fistula after pancreatoduodenectomy," Annals of Surgery, vol. 251, no. 5, pp. 932-936, 2010.

[31] M. Distler, S. Kersting, F. Rückert et al., "Chronic pancreatitis of the pancreatic remnant is an independent risk factor for pancreatic fistula after distal pancreatectomy," BMC Surgery, vol. 14, no. 1, article 54, 2014.

[32] N. Akamatsu, Y. Sugawara, M. Komagome et al., "Risk factors for postoperative pancreatic fistula after pancreaticoduodenectomy: the significance of the ratio of the main pancreatic duct to the pancreas body as a predictor of leakage," Journal of HepatoBiliary-Pancreatic Sciences, vol. 17, no. 3, pp. 322-328, 2010.

[33] M. Gagner and A. Pomp, "Laparoscopic pylorus-preserving pancreatoduodenectomy," Surgical Endoscopy, vol. 8, no. 5, pp. 408-410, 1994.

[34] L. W. Traverso and R. A. Kozarek, "Pancreatoduodenectomy for chronic pancreatitis: anatomic selection criteria and subsequent long-term outcome analysis," Annals of Surgery, vol. 226, no. 4, pp. 429-438, 1997.

[35] D. Kyuno, Y. Kimura, M. Imamura et al., "Pancreaticoduodenectomy for biliary tract carcinoma with situs inversus totalis: difficulties and technical notes based on two cases," World Journal of Surgical Oncology, vol. 11, no. 1, article 312, 2013.

[36] W.-H. Zhu, S. Li, D.-F. Zhang et al., "Risk factors and outcome of pancreatic fistula after consecutive pancreaticoduodenectomy with pancreaticojejunostomy for patients with malignant tumor," Chinese Journal of Cancer Research, vol. 22, no. 1, pp. 32-41, 2010.

[37] S. Y. Peng, J. W. Wang, J. T. Li, Y. P. Mou, Y. B. Liu, and X. J. Cai, "Binding pancreaticojejunostomy-a safe and reliable anastomosis procedure," HPB, vol. 6, no. 3, pp. 154-160, 2004.

[38] S. Y. Peng, J. W. Wang, W. Y. Lau et al., "Conventional versus binding pancreaticojejunostomy after pancreaticoduodenectomy: a prospective randomized trial," Annals of Surgery, vol. 245, no. 5, pp. 692-698, 2007.

[39] S. Mukherjee, H. M. Kocher, R. R. Hutchins, S. Bhattacharya, and A. T. Abraham, "Impact of hospital volume on outcomes for pancreaticoduodenectomy: a single UK HPB centre experience," European Journal of Surgical Oncology, vol. 35, no. 7, pp. 734-738, 2009.

[40] N. Pecorelli, G. Balzano, G. Capretti, A. Zerbi, V. Di Carlo, and M. Braga, "Effect of surgeon volume on outcome following pancreaticoduodenectomy in a high-volume hospital," Journal of Gastrointestinal Surgery, vol. 16, no. 3, pp. 518-523, 2012. 


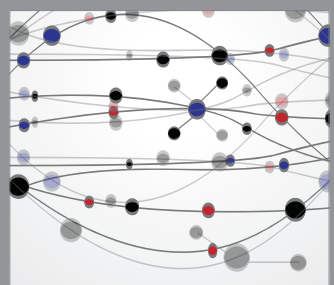

The Scientific World Journal
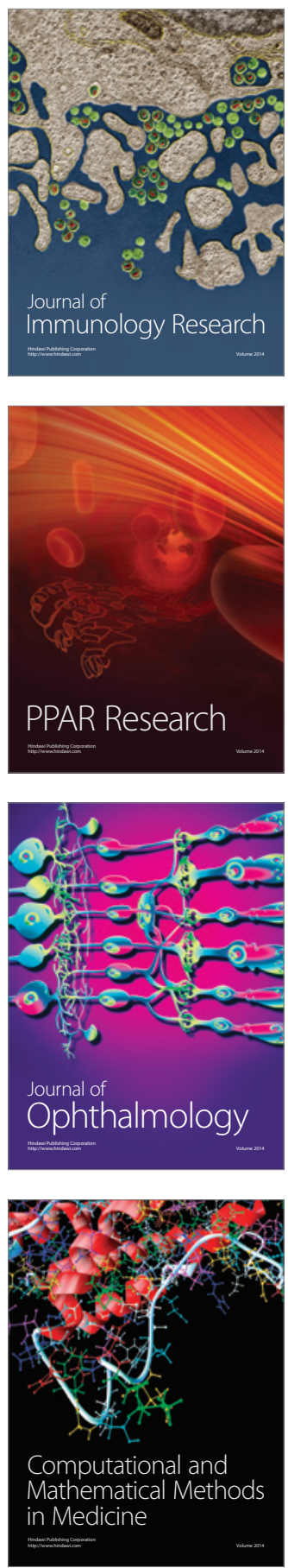

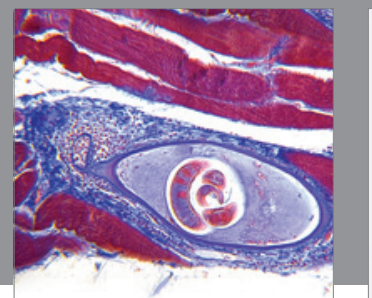

Gastroenterology

Research and Practice
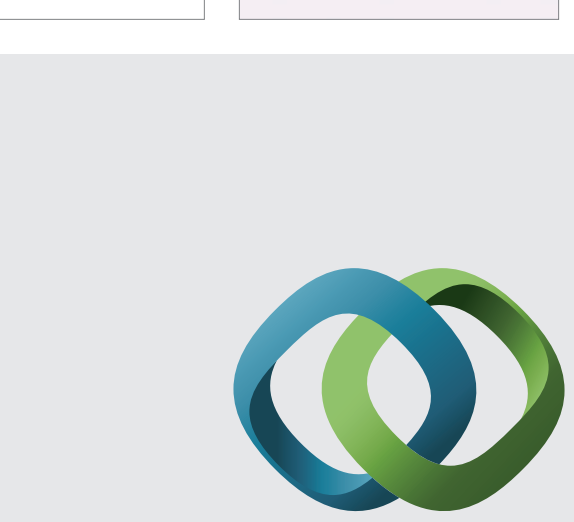

\section{Hindawi}

Submit your manuscripts at

http://www.hindawi.com
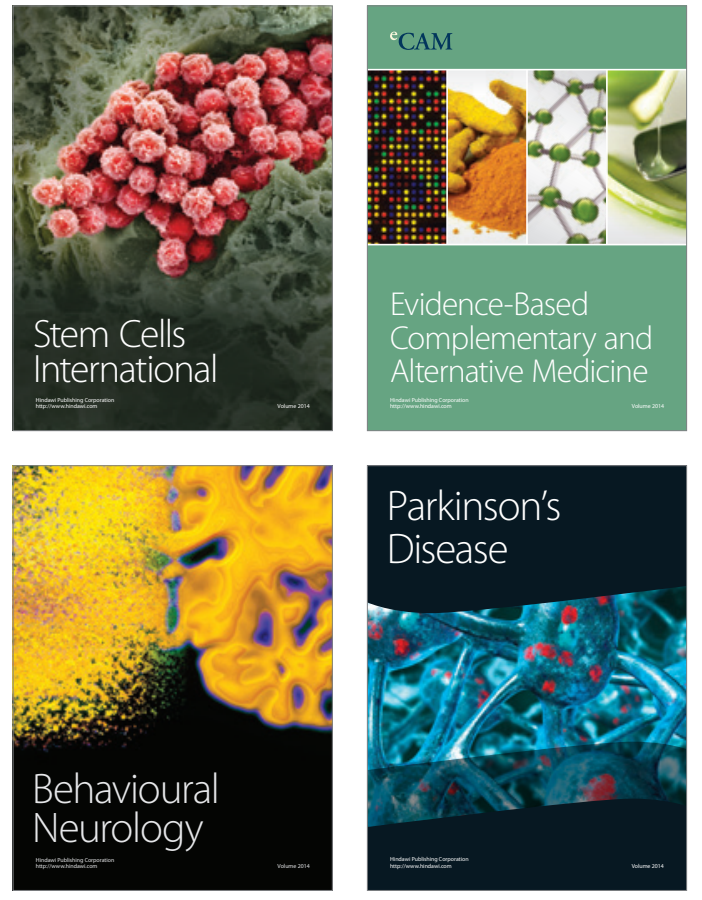
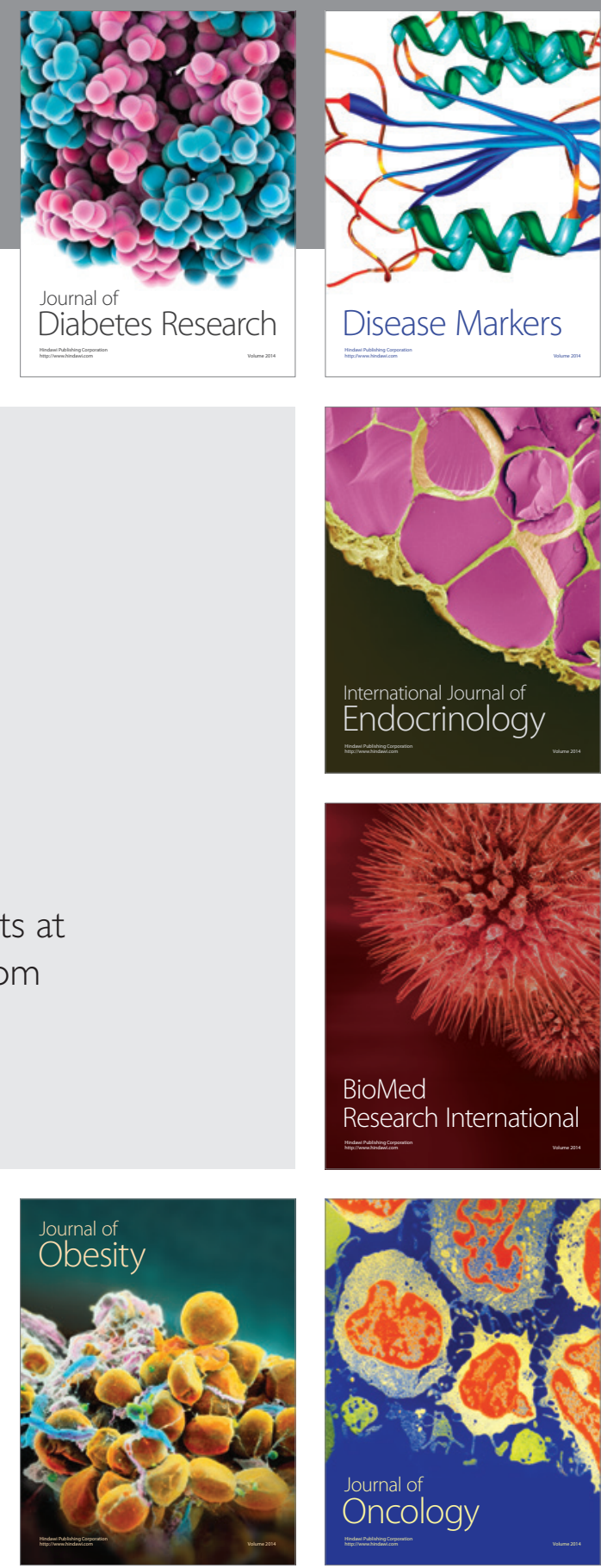

Disease Markers
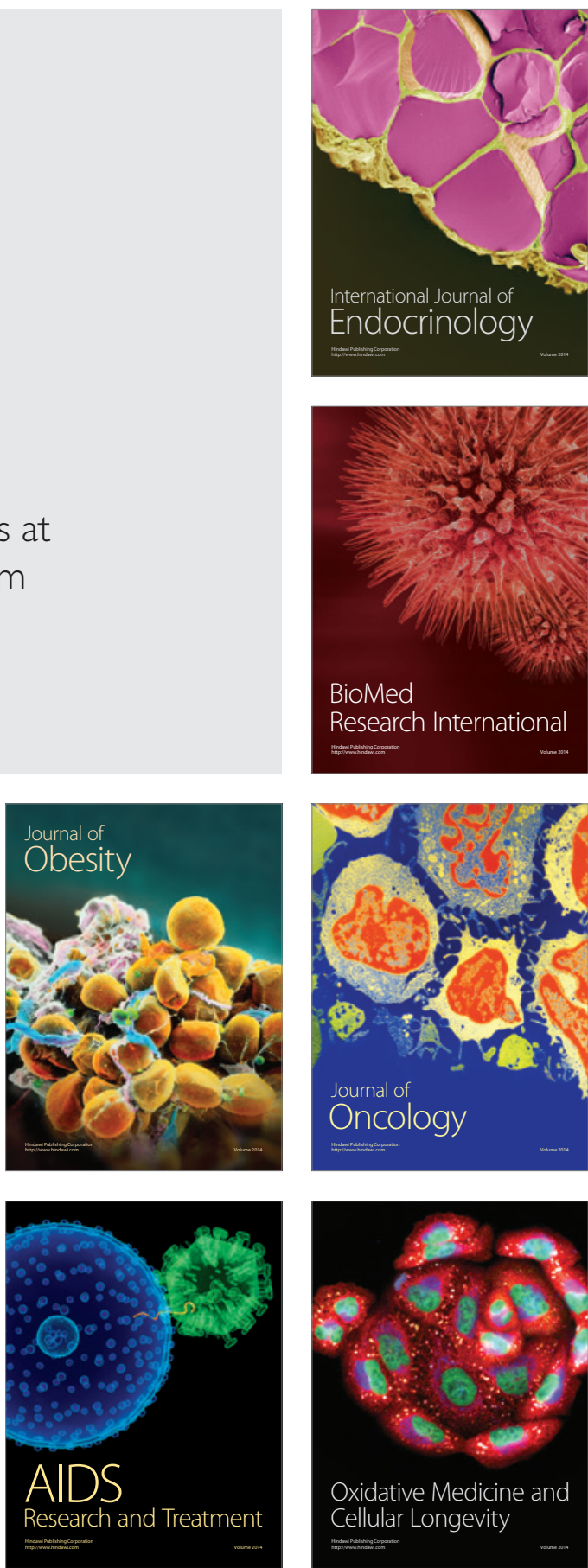